\title{
Healthcare Ecosystem Mapping in Primary Care: A Case Study in West Java, Indonesia
}

\author{
Mursyid Hasan Basri*, Desy Anisya Farmaciawaty, Ilma Nurul Rachmania, \\ Fransisca B. Widjaja, Aldo Fantinus Wiyana \\ ${ }^{1}$ School of Business and Management, Institut Teknologi Bandung, Indonesia \\ *Corresponding author. Email: mursyid@sbm-itb.ac.id
}

\begin{abstract}
Primary care is supposed to be the foundation to achieve universal health coverage. However, there is still a big gap in primary care service delivery in practice, especially in developing countries. The Healthcare system is portrayed as a complex setting consisting of multi-activities and multi-stakeholders. This research tries to describe the process flow of Indonesia's primary healthcare, key entities involved, and the linkage among them. This study employed a qualitative method. Semi-structured interviews were conducted with various types of primary care in West Java, Indonesia. Using the Healthcare Ecosystem Mapping framework, major entities are grouped into the interconnected-circle of delivery, financing, policymaking, and innovation. The interaction among entities are also described in BPMN. Findings showed that Indonesia's primary healthcare still focused more on curative rehabilitative action than promotive and preventive action. Besides, very few innovations are done in the healthcare delivery aspect. Further research should be conducted to give recommendation of a redesign process to improve this situation.
\end{abstract}

Keywords: Healthcare Ecosystem Mapping, BPMN, Indonesia primary healthcare.

\section{INTRODUCTION}

Healthcare ecosystem has been well known lately as one way to get a better understanding of the healthcare system. Term "healthcare ecosystem" is used because it represents engagement of all stakeholders that work together to define health needs, identify solutions and actions that are essential to increase quality of primary health care [22]. Through a healthcare ecosystem perspective, collaboration of all key stakeholders are created and in the end will provide a better patient experience and better health [15]. Batalden mentioned that the healthcare ecosystem should put patients as the center since patients are both the suppliers and consumers [1].

Stakeholders in every healthcare system are different depending on the characteristics of the healthcare system. In Indonesia, healthcare service divided into primary healthcare, secondary healthcare, and tertiary healthcare service. Primary healthcare is the first person/ place contacted by people to get the first information or help related to their health. Primary health care has three main elements: (1) primary care and essential public health functions as the core of integrated services, (2) multisectoral policy and action, (3) empowered people and communities [21]. In Indonesia, healthcare facilities are divided into two big categories, they are public healthcare and private healthcare. Primary care should provide preventive, curative, and promotive action [20]. Puskesmas and their auxiliary centres (pustu, puskel, polindes, poskesdes) are public primary providers of healthcare service in Indonesia [20]. While other primary health care from the private sector include solo general practitioner, private primary care clinic, midwifery clinic (bidan), and nursing clinic [20].

With more than 200 million citizens, Indonesia lacks healthcare personnel (nurses, doctors, midwife, pharmacists, nutritionist, therapists, and other). Number of healthcare personnel are also centered in urban areas. The ratio of primary healthcare to the number of citizens is $1: 15.000$. Which means one primary healthcare should provide healthcare service to 15.000 citizens [20]. Indonesia needs 15 times its current number of healthcare personnel to meet OECD standards [13]. More than half of primary healthcare facilities are puskesmas $(55.8 \%)$, with solo general practitioner $22.9 \%$ and medical centres $13.7 \%$ [20].

Primary care should be the front line of healthcare service in Indonesia, but many people hesitate to go to primary care and choose straight to secondary healthcare services. This made secondary and tertiary health care providers overwhelmed with the number of patients, especially during covid 19 pandemic. One of our interview's results shows that primary care in Indonesia is more focused on doing curative action. For preventive and promotive action, each Puskesmas usually follows work plans which are determined by the Director of Primary Care under Indonesian Ministry of health. This indicates that lack of innovation is done by Indonesian Primary Care especially puskesmas. 
In their white paper, Wyman stated that key principles needed for Indonesia's healthcare ecosystem are focus on health and preventive activities, leverage digital technology to give remote rural areas access to healthcare services, improve domestic and clinical quality, and affordable spending through public-private cooperation [13].

This research will provide healthcare ecosystem mapping to find out actors that are involved and describe their task flow in primary healthcare services. This way, suggestions can be made to fill in the gap and at the end can increase the quality of primary healthcare services.

To achieve this research's goals, Business Process Modeling Notation will be used to describe the business process of each stakeholder in Indonesian Primary Healthcare Ecosystem Mapping.

Gomes mentioned that BPMN provides more applicative solutions for healthcare providers and its stakeholders [6]. The strengths of BPMN are when it comes to visualizing simple details such as allocation and sequence of tasks [19]. There is a lot of previous research that uses BPMN on healthcare. This research's novelty will be on mapping the healthcare ecosystem on Indonesia's primary healthcare and describing each stakeholder's business process using BPMN. Through this process, suggestions on how to improve Indonesia's Primary Healthcare system can be made.

\section{LITERATURE REVIEW}

\subsection{Healthcare Ecosystem}

It is no doubt that healthcare plays a significant role in the life of a nation. Healthcare ecosystem itself involves lots of activities and stakeholders that have their own role and interests. There are many stakeholders involved in the healthcare system and they should be classified according to their similarities [23]. Iyawa mentions that patients should participate in the delivery of healthcare services [8]. This was supported by Batalden (2018) who rethinks healthcare as a coproduced service as an aspect in describing the healthcare system. He mentioned that patients should be in the center of the healthcare system, because they are both suppliers and consumers. Health research initiatives have evolved from user-centered into collaborative partnership of different stakeholders [7].

Dai and Tayur (2019) categorized the complex stakeholders of the healthcare ecosystem into four circles: delivery circle, financing circle, policymaking circle, and innovation circle [4]. Understanding the healthcare ecosystem becomes very important because all healthcare organizations are interconnected with each other. Healthcare's stakeholders are integral parts of healthcare processes [11].

Organizations need to understand the micro, meso and macro level institutions of their service ecosystem; react to institutional changes imposed by other actors; and proactively adapt with the changes [15]. Macro level deals with how to match supply and demand of healthcare services, micro level deals with the operations of specific healthcare, while meso level connects micro and macro level. But do not generalize this definition because each healthcare system has different and unique stakeholders in each level [4].

By understanding the healthcare ecosystem of specific healthcare systems, steps needed to be taken to increase the quality of healthcare service can be made.

\subsection{Healthcare and Innovation}

The changing healthcare industry needs new paradigms and innovation of its core business processes [18]. The advancement of technology increased the chances of the healthcare industry to innovate. Iyawa came up with the term digital health innovation ecosystem which can be defined as a network of digital health communities consisting of interconnected, interrelated, and interdependent digital health stakeholders, healthcare institutions, and healthcare devices situated in a digital health environment [8].

One definition of innovation is ability creating new ideas [5]. Healthcare innovation can be defined as the introduction of a new concept, idea, service, process, or product aimed at improving treatment, diagnosis, education, outreach, prevention and research, and with the long term goals of improving quality, safety, outcomes, efficiency and costs [14]. If the concept of healthcare innovation can be well defined, then it will become easier for health policymakers and practitioners to evaluate, adopt and prioritize healthcare innovations [14].

Several mechanisms that block healthcare innovation processes such as lack of leadership, restrictive rules for collaboration with industry, financial issues and procurement mechanisms, as well as insufficient involvement of patients [9]. It is important to understand the healthcare system's stakeholder in healthcare innovation. Because healthcare innovation should help patients to easily get healthcare service they needed and on the other hand help other stakeholder to perform their duties more effectively [14] 


\subsection{Business Process Model Notation}

BPMN is an industry standard used by engineers, analysts, and managers to picture it's business process in many domains [16]. The purpose for the BPMN development was to create a simple mechanism that was able to create models of complex business processes. In order to achieve these two aspects, the approach was to organize a graphic notation within specific categories [17].

\section{METHODOLOGY}

This study employed a qualitative method. For this preliminary research, a desk study is completed to conduct initial primary healthcare ecosystem mapping in West Java, Indonesia. Afterwards, semi-structured interviews via video conferencing were done. The objective of interview questions was to develop in-depth understanding of how is the delivery process in the healthcare services, how is the health financing mechanism, what regulations are govern, innovations in healthcare services, which actors are involved and what other processes that occur in primary healthcare services. Subsequently, all interviews are transcripted and coded to describe all processes and players that are involved in the healthcare ecosystem.

Table 1. Respondents Information

\begin{tabular}{|c|c|c|c|c|}
\hline $\begin{array}{c}\text { Res } \\
\text { pon } \\
\text { dent }\end{array}$ & $\begin{array}{c}\text { Primary } \\
\text { Healthcare } \\
\text { Type }\end{array}$ & $\begin{array}{c}\text { Intervie } \\
\text { wees } \\
\text { Specializ } \\
\text { ation }\end{array}$ & $\begin{array}{c}\text { Location of } \\
\text { Primary } \\
\text { Healthcare }\end{array}$ & $\begin{array}{c}\text { Serving } \\
\text { BPJS } \\
\text { Patients? }\end{array}$ \\
\hline R1 & $\begin{array}{c}\text { Public Primary } \\
\text { Healthcare }\end{array}$ & Doctor & Sub-urban & Yes \\
\hline R2 & $\begin{array}{c}\text { Public Primary } \\
\text { Healthcare }\end{array}$ & $\begin{array}{c}\text { Pharmaci } \\
\text { st }\end{array}$ & City & Yes \\
\hline R3 & $\begin{array}{c}\text { Private Medical } \\
\text { Clinic }\end{array}$ & $\begin{array}{c}\text { Top } \\
\text { Manage } \\
\text { ment }\end{array}$ & City & Yes \\
\hline R4 & $\begin{array}{c}\text { Private Medical } \\
\text { Clinic }\end{array}$ & $\begin{array}{c}\text { Doctor, } \\
\text { Manage } \\
\text { ment }\end{array}$ & Sub-urban & Yes \\
\hline R5 & $\begin{array}{c}\text { Private Medical } \\
\text { Clinic }\end{array}$ & $\begin{array}{c}\text { Toptor } \\
\text { Manage } \\
\text { ment }\end{array}$ & Rural & No \\
\hline Practice of GP & $\begin{array}{c}\text { Poctor } \\
\text { Individual }\end{array}$ & City & No \\
\hline
\end{tabular}

Table 1 presents the respondents information in this study. The respondent subject selection basis was to report insights from a cross-section of primary healthcare that varies in type (Public vs Private), location (City vs Sub- urban vs Rural), universal health coverage (BPJS vs Non BPJS). The interviewees also varied in background from doctor, pharmacist and also the top level management of the healthcare providers.

\section{ANALYSIS AND DISCUSSION}

According to the healthcare ecosystem mapping framework presented by Dai and Tayur (2019), the healthcare ecosystem is divided into four connected circles which are, healthcare delivery, policy making, financing and innovations. Furthermore, in Figure 1 we highlight key entities and the relationship among them in the primary healthcare settings.

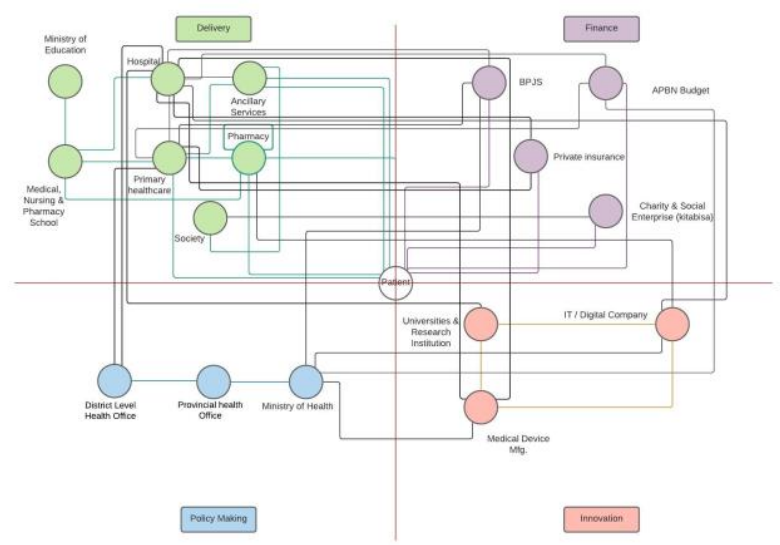

Figure 1. Healthcare Ecosystem Mapping in Indonesian Primary Healthcare

\subsection{Delivery}

The first circle describes the key entities involved in delivering healthcare to the patient. Primary healthcare delivery in Indonesia is divided in two types, public primary healthcare and private primary healthcare. Public primary healthcare consists of puskesmas and the auxiliary center, while private primary healthcare includes private medical clinics, individual practice of GP and midwife. Private primary care providers mostly operate on an independent basis, some private GP or private clinics will collaborate with BPJS Health to serve BPJS patients. Primary healthcare performs two main activities which are individual health effort (UKP) and community health efforts (UKM). Individual health efforts cover the curative and rehabilitative practices, while the community health efforts cover the promotive and preventive practices. The primary healthcare is staffed at least by the general practitioners, nurses, pharmacists and the administrative staff. In the bigger size of the primary healthcare provider, usually also supported by midwives, dentists, nutritionists. Other key entities in the delivery circle are solitaire pharmacy, ancillary services such as medical laboratory, school that provide clinicians, also the Ministry of Education, who provides guidance of health programs and 
awareness at the school level and the community itself who received the healthcare delivery.

According to WHO (2020), healthcare delivery needs to be timely, efficient, fair and integrated. However, in practice there are problems, such as long waiting time [10], medicine procurement and inventory issues [2], quality of care [12]. R2 and R3 describe how to overcome the long queue, they establish registration through hotline whatsapp. In R2, patients need to register through the hotline before coming to their healthcare facility. The patients must explain their symptom, then the clinician will take first anamnesis. If the patient requires further physical examination, the patient will receive the queue number as well as the appointment date to see the doctor. If the patient does not require further examination, the patient will be directed to the online consultation. At first, they did this because of the pandemic situation to reduce crowds of people, but also it can help to reduce the patient waiting time. However, R1, R4 and R5 still use the conventional system of registration, in which a patient needs to register on-site in the healthcare facility. Moreover, R1, R4 and R5 point out that online registration is still difficult to implement due to many of their patients not having cell phones.

The patient pathway starts from the primary healthcare facilities to the secondary referral hospitals and last is tertiary referral hospital. Without a referral letter, a BPJS patient is not allowed to seek treatment directly at a hospital or specialist clinic, except in an emergency situation. According to BPJS, there are 144 diagnoses that must be treated in level primary healthcare. Referral ratio has become one of the performance indicators of primary healthcare. R1 stated that they cannot treat all the 144 diagnoses in their facility due to limitation of medical devices and equipment available.

In R1, primary healthcare also collaborates with hospitals to improve the competence of clinicians in primary healthcare in the form of sharing knowledge. Moreover, the primary healthcare also collaborates with the local community associated with the health efforts.

For the community health efforts (UKM), all respondents agreed that promotive and preventive practices in their primary healthcare service are not implemented maximally. The practices still focus more on the curative and rehabilitative. According to R1 the promotive and preventive activities are still focused on activities inside the building such as counseling. There have not been many promotive and preventive activities carried outside the building. Moreover, R1 describes that the home visit activity postponed temporarily due to pandemic. In line with R1, because many community efforts were postponed due to the pandemic, R2 and R3 modify the community efforts to the online basis. R2 and R3 started to do counseling and education to raise awareness via instagram platform, establish whats app group for community, etc.

The key barriers in implementing promotive and preventive activities such as limited human resources and lack of infrastructure and financing to support promotive and preventive actions. Another barrier was the less massive socialization about the promotive and preventive programs, lack of emphasis on the healthy paradigm starts from family approach and communities have not been fully involved. This is in line with data from the Ministry of Health 2020, that individual health efforts (UKP) and community health efforts (UKM) are unbalanced. UKP activities are greater than the UKM, which is proven by proportion of financing, health professional resources, success rate indicator of promotive and preventive also the authority aspect. Whereas, the UKM and UKP practices should be undertaken continuously, balanced and integrated in accordance with Ministry of Health Regulation No 43 2019 regarding Primary Healthcare. Community health efforts should cover strengthening health awareness, the community empowerment and family approach. Individual health efforts are implemented by universal health coverage, so that primary healthcare stands as the gatekeeper to achieve the strategic plan "Indonesia Sehat".

\subsection{Policy Making}

The second circle is policy making, which shapes the regulation and policies regarding healthcare services. This circle consists of three key entities that are District Health Office, Province Health Office and the highest is the Ministry of Health. The task and the responsibilities are shared on an integrated basis between central, provincial, and district levels of government. According to Regulation No. 38 of 2007, at least three functions are defined: legislation and regulation, financing, and service delivery. Besides, monitoring and evaluation of health progress and performance are essential to ensure that priority actions and decisions are implemented as planned.

The Ministry of Health is responsible for the strategic direction, setting of standards, regulation, and ensuring the availability of financial and human resources. Provincial Health Offices are responsible for providing technical support and monitoring of district health services, and coordinate cross-district health issues within the province. While, District Health Offices are responsible for management of district public healthcare. 
Policy making also serves as regulators for permit, such as licence practice for clinicians, operational permit for private healthcare providers, also regulation permit for medical devices and pharmaceutical products. In 2014, the Ministry of Health required the public primary healthcare to be accredited according to a national accreditation standard. The accreditation process will improve quality of administrative management, management of public health programmes and quality of health-care services. In the future, the private primary healthcare providers are also expected to be accredited.

\subsection{Financing}

Financing circle consists of entities that provide and allocate funds for healthcare activities, which are BPJS, Government, Private Insurance, Charity and Social Enterprise. For public primary healthcare and private primary healthcare that serve BPJS patients will receive the funding from BPJS by capitation basis. Capitation is the amount of monthly payments paid in advance by BPJS Kesehatan to the primary healthcare providers based on the number of registered participants without considering the type and number of health services provided. However, the funding allocation from BPJS is mainly used for curative rehabilitative care. The allocation for community efforts are relatively low compared to the curative rehabilitative care. Only less than $1 \%$ goes to promotion and prevention programs. In $2016,67 \%$ of the Indonesian population joined the National Health Insurance system [3].

The decentralization policy in Indonesia influences the financial flows in public primary healthcare. The Ministry of Health allocates health funding through pooling of fund mechanisms. From the central level and then transferring pooled funds to provincial and district level. The public primary healthcare receive Health Operational Costs (Biaya Operasional Kesehatan / BOK). According to Ministry of Health Regulation 82 of 2015, the BOK is channelled through a Special Allocation Fund and transferred to the District Health Office, and subsequently distributed to the public primary healthcare. The BOK aims to support healthcare programmes that link to the national targets of the health system, especially those delivered by the primary healthcare. R1 and R2 used the BOK as source of funding for the promotive and preventive activities. In contrast, R4 pointed out that in the private public healthcare, they did not receive special funds particularly for promotive and preventive activities as the public healthcare received. So, the challenge in the capitation scheme for private primary healthcare is how to manage all the funds for both promotive, preventive and curative rehabilitative services. Moreover, R4 stated that the larger registered participants, the greater amount of capitation that will be received. This indirectly causes healthcare providers with large capitation could provide better services, because they have sufficient funds.

Some public healthcare facilities have a status of semi-autonomous public budgetary units (Badan Layanan Umum Daerah / BLUD). Healthcare facilities with BLUD status have greater autonomy in managing revenue earned as well as budgetary allocations. Besides from the government budget, primary healthcare providers receive payments from patients in direct (who are not covered by any scheme) with a fee-for-service scheme. Also, primary healthcare providers receive payment fee-for-service from the third party such as private insurance companies or charity and social enterprises.

\subsection{Innovation}

The innovation circle consists of the entities that develop new drugs, therapies, medical devices, and new business models and operational approaches. The objective of this circle is to ensure the healthcare providers and research institutions continue to develop new technologies and that organizations continue to innovate their operations and business models. The entities in this circle are universities and research institutions, medical devices manufacturer and IT or digital company.

All respondents agreed that not many innovations are implemented in the primary care level. Although innovation in digital technology has begun to be developed in the primary care level. However, in practice there are still many obstacles to face. Nowadays, more than 120 countries have developed national policies and strategies for e-Health, telemedicine and digital health [22]. Currently Indonesian government provides a national online medical record system (PCare) at all primary care facilities serving BPJS-Kesehatan members. Although the form of the online medical record system is still undergoing continuous development, the aim is to create integrated referral information for primary, secondary and tertiary care. Moreover, there is also an application particularly for information management systems in puskesmas called e-Pus. Furthermore, in 2019 West Java Province introduced the M-Pus (Mobile Puskesmas) which aims to provide healthcare services in areas that are difficult to access. Indonesia has also established a national information system (SIKNAS) and district-level health information systems (SIKDA). SIKDA should aim to support SIKNAS, but the decentralization of the health sector has negative impacts. With decentralization, the development of local health information systems is the responsibility of local 
governments. However, the lack of guidance on health service standards (including on data and information) has resulted in different perceptions. This causes the health information system built to be not standard either. According to respondents, R1, R2, R3 and R4 strongly agree that the current digital information system in primary healthcare is still fragmented. Not all of the existing applications are integrated, so that their utilization cannot be maximized.

Besides the innovation from the digital aspect, innovation in the business aspect is equally important. R3 describes that they collaborate with universities and research institutes to do continuous improvement in healthcare management so that they can continue to provide excellent service effectively and efficiently.

\subsection{Interactions among Circles of Primary Care Entities}

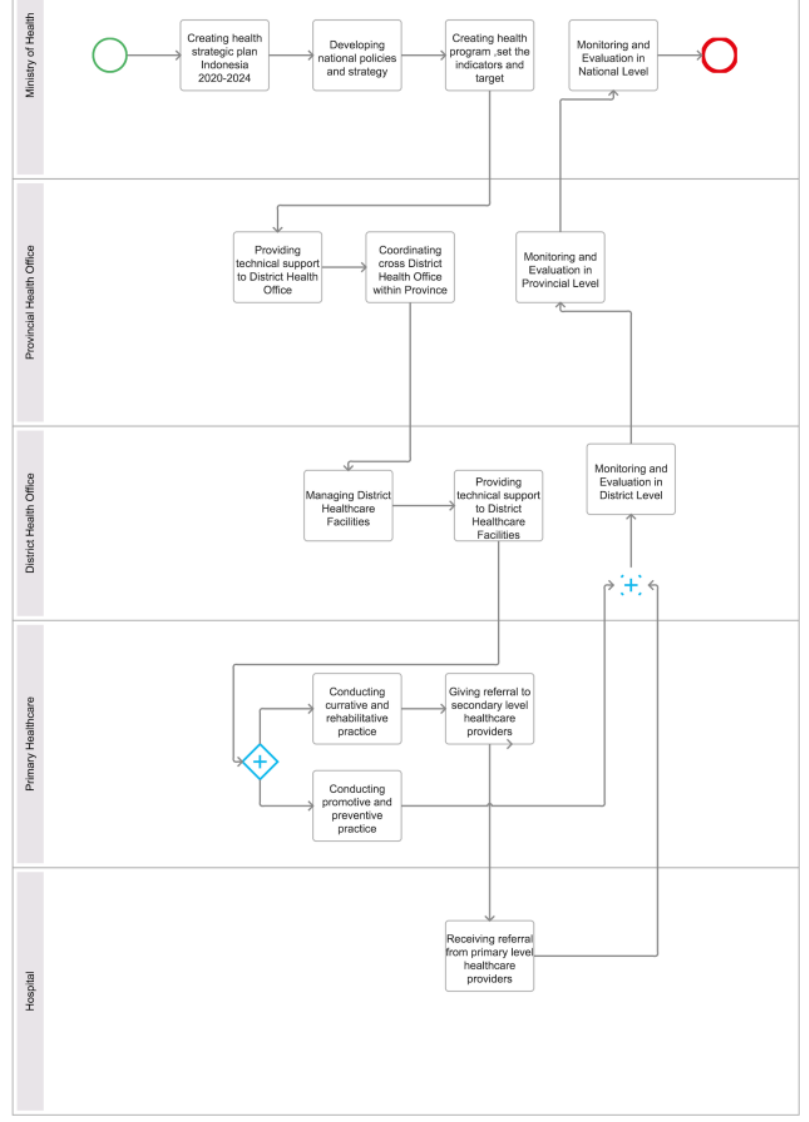

Figure 2. BPMN of Interaction among Delivery and Policy Making Subloops

According to Figure 1, the interactions are present in the form of lines within entities in the circle and intra circle. In the first subloop between delivery and policy making interactions are presented in BPMN Figure 2. The government role as a regulator is indeed very important. However, commitment and leadership within the health sector beyond the health sector are also essentials. The involvement of the Mayor or Governor, other political leaders (for example, parliamentarians), civil society and influential community, religious and business figures are significant in strengthening the primary care service. Furthermore, monitoring and evaluation health programs are also prominent to ensure all the activities are implemented in accordance with the goals and targets that have been set. The results of monitoring and evaluation can also be used as a reference in determining further health planning. In the subloop between delivery and financing, the interactions mostly focus on financing flow. According to R4, capitation schemes paid by BPJS are usually received on time. The capitation tariff in each primary healthcare is differ depending on several factors such as human resource, facilities and infrastructure, scope of service and commitment. R4 receives a capitation of $\mathrm{Rp}$. 8,000.00 (eight thousand rupiah) per BPJS participant. This tariff applies to primary care that has at least 2 (two) doctors, with no dentist and opening service time is less than 24 (twenty four) hours every day.

In the subloop innovation, mostly innovations in the healthcare aspects are done individually by the pharmaceutical companies, medical devices manufacturers and so on. Furthermore, all the interviewees agreed that practically no innovations are done by primary healthcare providers. Adoption of digital technologies are still limited due to knowledge, technological and infrastructural barriers. Existing applications and health information systems are still fragmented and not yet capable of integrating data from end-to-end processes.

\section{CONCLUSION}

Primary healthcare that serves as the first point-ofcontact, plays an important role in the overall health system. This study highlights the process and activity lies in primary healthcare scope. Major entities are identified, the relationship and connection between each entity are described. Several issues arose based on this study, such as: The society should start to enhance more on promotive and preventive efforts in order to achieve better health outcomes, rather than only pursuing curative rehabilitative programs; Ensuring the adequate financing and other resources to support healthcare services are essentials; Collaborative innovations between all key entities to improve quality of care, effectiveness and efficiency; The role of government not only as the regulators, but include leadership that engages with a variety of stakeholders. All of those issues are intimately interrelated, and impact one to another. They need to be an integral part of the national 
health strategy, prioritized, optimized to ensure achieving universal health coverage.

\section{ACKNOWLEDGMENTS}

The authors would express gratitude for receiving funding from the P3MI program at Institut Teknologi Bandung.

\section{REFERENCES}

[1] Batalden, P. J. B. (2018). Getting more health from healthcare: quality improvement must acknowledge patient co production - an essay by Paul Batalden. $362, \mathrm{k} 3617$.

[2] Bogaert, P., Bochenek, T., Prokop, A., \& Pilc, A. (2015). A qualitative approach to a better understanding of the problems underlying drug shortages, as viewed from Belgian, French and the European Union's Perspectives. PloS one, 10(5), e0125691

[3] BPJS Kesehatan. (2016). Health Social Security Agency Report

[4] Dai, T., \& Tayur, S. (2019). Healthcare operations management: A snapshot of emerging research. Manufacturing Service Operations Management

[5] Du Plessis M. The role of knowledge management in innovation. J. Know Mgmt 2007;11: 20-29

[6] Gomes, João \& Portela, Filipe \& Santos, Manuel. (2018). Introduction to BPM approach in Healthcare and Case Study of End User Interaction with EHR Interface. Procedia Computer Science. 141. 519-524. 10.1016/j.procs.2018.10.132.

[7] Holgado, A.G., Marcos, S., Therón, R., \& GarcíaPeñalvo, F. (2019). Technological Ecosystems in the Health Sector: a Mapping Study of European Research Projects. Journal of Medical Systems, 43, $1-11$.

[8] Iyawa, G., Herselman, M., \& Botha, A. (2016). Digital Health Innovation Ecosystems: From Systematic Literature Review to Conceptual Framework. Procedia Computer Science, 100, 244252.

[9] Larisch, Lisa-Marie \& Amer-Wåhlin, Isis \& Hidefjall, Patrik. (2016). Understanding healthcare innovation systems: the Stockholm region case. Journal of Health Organization and Management. 30. 1221-1241. 10.1108/JHOM-04-2016-0061.

[10] Liu, N. and D'Aunno, T. (2012), The Productivity and Cost-Efficiency of Models for Involving Nurse Practitioners in Primary Care: A Perspective from Queueing Analysis. HSR: Health Services Research 7:594-613.

[11] Mohrman, Susan \& Shani, Abraham. (2014). Healthcare: An Ecosystem in Transition. 10.1108/S2045-060520140000004005.
[12] Mosadeghrad, A. M. (2014). Factors influencing healthcare service quality. International journal of health policy and management, 3(2), 77.

[13] Oliver Wyman. (2018). The Future of Indonesian Healthcare Ecosystem: The Outlook of 2030. [White Paper]. https://www.oliverwyman.com/content/dam/oliverwyman/v2/publications/2018/october/the-future-ofthe-indonesian-healthcare-ecosystem.pdf

[14] Omachonu, Vincent \& Einspruch, Norman. (2010). Innovation in Healthcare Delivery Systems: A Conceptual Framework. The Innovation Journal: The public sector Innovation Journal. 15.

[15] Pop, Oana \& Leroi-Werelds, Sara \& Roijakkers, Nadine \& Andreassen, Tor. (2018). Institutional types and institutional change in healthcare ecosystems. Journal of Service Management. 29. 10.1108/JOSM-02-2017-0041.

[16] Recker, J. (2010). Opportunities and constraints: the current struggle with BPMN. Business Process Management Journal, 16(1),181-201. doi: $10.1108 / 14637151011018001$

[17] S. a White, "Introduction to BPMN," BPTrends, no. c, pp. 1-11, 2004.

[18] Serbanati, Alexandru \& Medaglia, Carlo \& Ceipidor, Ugo. (2011). Building Blocks of the Internet of Things: State of the Art and Beyond. 10.5772/19997.

[19] Stitzlein, C., Sanderson, P., \& Indulska, M. (2013). Understanding healthcare processes: An evaluation of two process model notations. Proceedings of the Human Factors and Ergonomics Society Annual Meeting, 57(1), 240-244. https://doi.org/10.1177/1541931213571053

[20] WHO. (2017). Primary Healthcare Systems Case Study of Indonesia

[21] WHO. (2018). Primary Healthcare: closing the gap between public health and primary care through integration.

[22] WHO. (2020). Operational Framework for Primary Healthcare

[23] Wu, Juhua \& Wang, Yu \& Tao, Lei \& Peng, JiaMin. (2019). Stakeholders in the healthcare service ecosystem. Procedia CIRP. 83. 375-379. 10.1016/j.procir.2019.04.085. 